\title{
«Cahiers Mérimée» 7
}

\section{Michel Arrous}

\section{(2) OpenEdition \\ Journals}

\section{Édition électronique}

URL : http://journals.openedition.org/studifrancesi/5392

DOI : 10.4000/studifrancesi.5392

ISSN : 2427-5856

\section{Éditeur}

Rosenberg \& Sellier

\section{Édition imprimée}

Date de publication : 1 décembre 2016

Pagination : $547-548$

ISSN : 0039-2944

\section{Référence électronique}

Michel Arrous, « «Cahiers Mérimée» 7 », Studi Francesi [En ligne], 180 (LX | III) | 2016, mis en ligne le 01 janvier 2017, consulté le 18 septembre 2020. URL : http://journals.openedition.org/studifrancesi/5392 ; DOI : https://doi.org/10.4000/studifrancesi.5392

Ce document a été généré automatiquement le 18 septembre 2020.

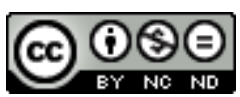

Studi Francesi è distribuita con Licenza Creative Commons Attribuzione - Non commerciale - Non opere derivate 4.0 Internazionale. 


\title{
«Cahiers Mérimée» 7
}

\author{
Michel Arrous
}

\section{RÉFÉRENCE}

«Cahiers Mérimée» n. 7, 2015, 215 pp.

1 L'activité du séminaire Mérimée qu'anime à Paris III Antonia FONYI ne faiblit pas. En témoigne cette livraison dont la variété est due à une solide érudition aussi bien qu'à de pertinentes analyses. Si la démarche savante de Mérimée a déjà fait l'objet de réflexions générales (P. Glaudes, Mérimée et le bon usage du savoir, 2008), ses connaissances comme ses interrogations méritent des investigations approfondies. Dans L'horizon du savoir. Mérimée et l'archéomanie celtique (pp. 9-29), Alexandre BonAFos a choisi d'examiner ce que l'inspecteur général des Monuments historiques a dit, au retour de sa tournée de 1839 en Corse, des mégalithes qui sont «l'objet archéologique par excellence dans l'enquête mériméenne» (son étude de 1836 sur le monument de l'île de Gavr'Innis aurait pu être évoquée). À une époque où les hypothèses allaient bon train, Mérimée se garde de l' "archéomanie aiguë» dont il a vu quelques exemples pendant sa tournée bretonne de 1835. Sont précisément évoquées les recherches et les spéculations sur le passé celtique de la nation et la fin de la mythologie druidique. Dans sa démarche descriptive, Mérimée ne cède pas à la «tentation de la rêverie savante»: devant les alignements de Carnac, «il a soin de résister aux sirènes qui entraînent le naufrage de la raison». Mérimée ne se désintéressera pas de la question sur laquelle il reviendra dans deux articles en 1852 et 1853. Sa leçon reste d'actualité dans un temps où perdurent "certaines théories abracadabrantesques sur les qualités radiesthésiques ou l'origine extraterrestre des sites mégalithiques». Alors qu'on ne disposait sur Mérimée père que de l'ancien ouvrage de Pinet, Sidonie LEMEUX-FRAITOT apporte d'innombrables rectifications et précisions, à commencer par la curieuse orthographe de son prénom (Léonord, l'autre Mérimée, pp. 33-57). Sont passés en revue, non sans de notables apports, la formation et la carrière du peintre, ses œuvres, ses recherches et travaux, en Hollande et en Italie, qui feront de lui un des premiers historiens d'art français, son amitié avec les peintres Gérard et Prud'hon, sa carrière administrative à partir de 1794, 
et notamment son rôle de Secrétaire de l'École des Beaux-Arts, ainsi que les missions que lui confia en 1817 et 1819 Decazes, son ami proche. Revenant sur les adaptations lyriques de l'œuvre de Mérimée, Olivier BARA convoque deux ouvrages fort populaires au XIx ${ }^{e}$ siècle, pour étudier les rapports qu'entretiennent avec leur source littéraire directe le "grand opéra» et l'opéra comique (Deux opéras pour un roman. "Chronique du règne de Charles IX", "Le Pré-aux-Clercs", "Les Huguenots", pp. 61-75). À la différence de Scribe qui tire parti de l'intrication de l'intrigue amoureuse et du conflit politicoreligieux dans le livret des Huguenots (1838), Eugène de Planart, librettiste du Pré-auxClercs (1832), décale l'intrigue et congédie la violence historique, ne retenant que le chapitre V du roman. Dans l'opéra-comique, Planart et Hérold «vont dans le sens d'un évitement de l'histoire», tandis que dans le grand opéra Scribe et Meyerbeer, au lieu d' "effleurer les sujets», mettent en scène les dangers du fanatisme. Mais de ces deux ouvrages lyriques, aucun «ne parvient à intégrer pleinement la tension fondatrice du récit mériméen». Dans l'Angleterre de la décadence et du symbolisme, au temps du Yellow Book, périodique fameux, la réception de Mérimée a connu un vif regain grâce à trois médiateurs francophiles qui furent des essayistes à la mode: Pater, Wilde et Symons. Bénédicte coste présente le rôle de ces commentateurs avertis des courants littéraires modernes (Les "Yellows Nineties" de Mérimée, pp. 77-97). Dans son compte rendu des prétendues réponses de l'Inconnue de Mérimée, Wilde voit en ce dernier un artiste qui s'amuse à dénoncer la mystification tout en la louant. Pater revient sur ces " fascinating forgeries» et corrige l'interprétation en insistant sur la figure de l'écrivain qui s'avance masqué. Dans son «Prosper Mérimée» qui servit d'abord d'introduction à sa traduction de Carmen et de Colomba (1901), Symons tente un portait complet de Mérimée, en partie inspiré de Pater, Taine et Sainte-Beuve, et traite lui aussi des mystifications de Mérimée, mais aussi de sa misanthropie, de son impersonnalité, de sa technique d'écrivain et du tarissement de l'inspiration, l'érudition l'emportant sur l'art. Bien que la violence soit une constante de son œuvre, «les spécialistes du romantisme violent semble se désintéresser de Mérimée» constate Émilie PEZARD (Mérimée et le romantisme frénétique, pp. 99-117). Cette exclusion serait due à une définition générique illustrée par les «petits» romantiques dont l'ancrage politico-historique diffère de celui de Mérimée, même si l'écrivain n'est pas étranger à la mode littéraire de la violence, à la littérature horrifiante de 1820-1830. L'auteur de Tamango et de La Famille de Carvajal (dont la préface se rattache ironiquement au courant frénétique), est bien un auteur emblématique du romantisme violent, et même un initiateur avec La Guzla. Esther PINON a choisi un autre exemple d'écriture de l'excès où se retrouve dans le goût de la provocation et le plaisir de l'irrévérence qui caractérisent les habitudes langagières de l'écrivain athée, surtout quand il manie le blasphème, le juron et le jurement mêlés au rire (Par le ciel et l'enfer. Le blasphème dans le "Théâtre de Clara Gazul", pp. 119-137). On remarquera que les blasphèmes, anticléricaux, comiques ou énergiques, sont plus fréquents dans le théâtre de Mérimée que dans la plupart de ses récits. Thierry SANTURENNE propose une étude comparée de la valeur symbolique du serpent (L'apparition du serpent dans "Djoûmane" (Mérimée) et "Catalina" (Villiers de L'Isle-Adam), pp.139-153). Outre une plausible influence mériméenne sont relevées les analogies formelles et thématiques dans la représentation fantastique considérée «comme le vecteur d'une réflexion sur la violence que chaque être découvre en lui et réprime malaisément». Barbara DIMOPOULou expose la stratégie éditoriale mise en place pour soutenir et valoriser une œuvre de Mérimée, à une époque où notre auteur n'était pas encore un bon parti éditorial (Le "Théâtre de Clara Gazul, comédienne espagnole", dans les 
catalogues imprimés d'A. Sautelet et Cie libraires éditeurs entre 1826 et 1829, pp. 155-174). À noter, un intéressant excursus sur Hippolyte Fournier jeune qui édita la nouvelle version de Clara Gazul en 1830, avec l'aide de son frère, le fameux Henri.

Dans la section «Correspondance» figure, publiée par Jean CANAVAGGIO, une lettre inédite du 12 avril 1864 par laquelle Mérimée, bien informé de l'état de la question et de ses dessous, laisse entendre à l'archéologue corse Alexandre Grassi qu'il a peu de chances de participer à l'expédition scientifique du Mexique (pp.177-182). Antonia FONYI illustre «La vie des œuvres» avec «Mateo Falcone, film d'Éric Vuillard. Entretien avec le réalisateur» (pp.177-182). Dans ce film de 2008, sorti en 2014, le metteur en scène qui est aussi romancier a voulu se libérer du folklore corse («quincaillerie», «camelote») dont Mérimée serait un des créateurs, aussi a-t-il dépaysé son adaptation (le causse Méjean préféré au maquis de Porto-Vecchio) et privilégié les moments de violence, en se rangeant du côté de Fortunato, pour mieux rendre compte de la tension entre le père et le fils. Pp. 193-197, on trouvera, établie par Xavier BOURDENET, la «Bibliographie de la critique sur l'œuvre littéraire et historique de Mérimée» pour 2013, avec des compléments (1990, 2004, 2006, 2010 et 2011). 